\title{
PENERAPAN SISTEM CLOUD MANAJEMEN BANK SAMPAH DI PERUMAHAN TAMAN NURI KELURAHAN SINDANG SARI KABUPATEN TANGERANG
}

\author{
Muhamad Bahrul Ulum, Yunita Fauzia Achmad' Alivia Yulfitri, Lista Meria \\ Fakutas Ilmu Komputer, ${ }^{4}$ Fakultas Ekonomi dan Bisnis, Universitas Esa Unggul \\ Jalan Arjuna Utara No. 9 Kebon Jeruk, Jakarta Barat - 11510 \\ m.bahrul_ulum@esaunggul.ac.id
}

\begin{abstract}
To maintain or avoid environmental pollution, the village government campaigns for activities to the community to sort organic and non-organic waste. To support this program, the village government collaborates with waste collection companies in the form of waste banks to accommodate segregated waste, especially plastic bottles and cardboard / paper that the community has collected. Currently at Taman Nuri Housing, the waste bank management process is technically still manual, such as how to deposit, record and disburse waste bank funds. Waste bank management also does not have an updated report for the number of waste banks in each region and the number of citizen participation. In this community service program, a web-based cloud system will be implemented to fulfill waste bank management activities and this application can be used as a medium of information about waste banks. This waste bank management application utilizes cloud technology.
\end{abstract}

Keywords: waste bank, cloud, management

\begin{abstract}
Abstrak
Untuk menjaga atau menghindarkan pencemaran lingkungan, pemerintah desa mengkampanyekan kegiatan kepada masyarakat untuk memilah sampah organik dan non organik. Untuk mendukung program tersebut pemerintah desa menjalin kerjasama dengan perusahan-perusahaan penampung sampah dalam bentuk bank sampah untuk menampung sampah-sampah yang sudah terpilah khususnya botol-botol plastik dan kardus/kertas yang sudah di kumpulkan masyarakat. Saat ini di Perumahan Taman Nuri proses pengelolaan bank sampah secara teknis masih secara manual seperti cara penyetoran, pencatatan dan pencairan dana bank sampah. Pengelolaan bank sampah juga belum memiliki laporan update untuk jumlah bank sampah tiap daerah dan jumlah partisipasi warga. Pada program pengabdian masyarakat ini akan diterapkan sistem cloud berbasis web untuk memenuhi kegiatan manajemen bank sampah dan aplikasi ini dapat dijadikan sebagai media informasi mengenai bank sampah. Aplikasi manajemen bank sampah ini memanfaatkan teknologi cloud.
\end{abstract}

Kata kunci: bank sampah, cloud, manajemen

\section{Pendahuluan}

Perumahan Taman Nuri Kabupaten Tangerang sudah terdapat kelompok bank sampah yang proses pengelolaannya secara teknis masih secara manual. Anggota harus datang ke bank sampah untuk menyetorkan sampahnya tersebut dan dicatat dalam buku nasabah dan untuk pencairan dananya harus datang ke bank sampah tersebut. Saat ini pengelolaan bank sampah di Perumahan Taman Nuri belum memiliki laporan yang update mengenai sampah yang terbanyak di daerah mana saja dan masyarakat mana saja yang peran aktif dalam menjaga lingkungan. Maka dari itu pengembangan dan pemberdayaan di tempat ini sangat diperlukan untuk menjadikan lebih maju dan sejahtera, terutama dalam hal manajemen pengelolaan bank sampah.

Kegiatan ini mengajarkan masyarakat untuk memilah sampah serta menumbuhkan kesadaran masyarakat dalam pengolahan sampah secara bijak sehingga pada gilirannya akan mengurangi sampah yang diangkut ke TPA (Jastam, 2015) (Selomo et al., 2016). Pembangunan bank sampah ini harus menjadi momentum awal membina kesadaran kolektif masyarakat untuk memulai memilah, mendaur-ulang dan memanfaatkan sampah, karena sampah mempunyai nilai jual yang cukup baik, sehingga pengelolaan sampah yang berwawasan lingkungan menjadi budaya baru Indonesia (Suryani, 2014) (Sampah, 2015). Pada sistem yang sedang berjalan pada bank sampah saat ini prosesnya dalam pencatatan masih manual dalam melihat report hasil jumlah deposit sampah dan uang yang sudah terkumpul dapat dilihat dibuku tabungan. 


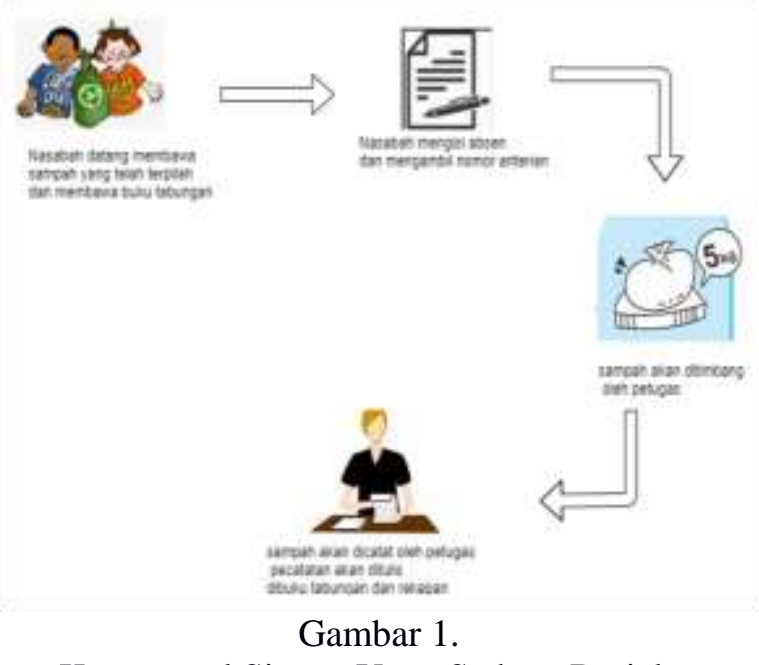

Konseptual Sistem Yang Sedang Berjalan

Alur proses saat ini yang sedang berjalan dimulai dari anggota mengisi absen dan mengambil nomor anterian dan menyerahkan ke petugas selanjutnya petugas penimbang akan menimbang sampah dan petugas pencatatat akan mencatat jumlah sampah dan uang yang sudah terkumpul.

Selain kondisi tersbut terdapat beberapa permasalahan yang terjadi dalam hal manajemen pengelolaan bank sampah diantaranya :

1. Masalah yang selama ini sering dihadapi pada bank sampah adanya tidak sesuainya pencatatan dalam jumlah sampah yang disetorkan

2. Untuk mengetahui informasi perubahan tabel harga sampah, backup data masih tercatat manual tidak amannya dalam penyimpan data

3. Pengelolaan bank sampah di Perumahan Taman Nuri tidak memiliki laporan yang update mengenai sampah yang terbanyak di daerah mana saja dan masyarakat mana saja yang peran aktif dalam menjaga lingkungan.

4. Pendataan nasabah bank sampah dilakukan secara manual atau berbasis kertas, dimana petugas mencatat jumlah sampah yang ditabung oleh masyarakat, sehingga terjadi ketidak akuratan data dan mengakibatkan keterlambatan dalam melakukan pembuatan laporan.

5. Belum adanya sistem manajemen pengelolaan bank sampah berbasis IT karena hasil pencatatan data dan laporan masih disimpan dalam bentuk paper based mengakibatkan penumpukan data tabungan bank sampah yang tidak teratur.

6. Belum adanya pelatihan manajemen pengelolaan bank sampah.

7. Belum adanya pelatihan dalam penggunaan komputer untuk meningkatkan kualitas SDM pengelola bank sampah.
8. Kesadaran masyarakat untuk peduli terhadap lingkungan khususnya dalam mengelola sampah masih perlu ditingkatkan.

Untuk itu perlu kiranya sebuah pelatihan manajemen pengelolaan bank sampah berbasis IT dan pembuatan sistem cloud untuk manajemen pengelolaan bank sampah di Perumahan Taman Nuri (Ulum \& Laday, 2016) (Alimuddin Yasin, MZ Yumarlin, 2017). Tujuan dari PKM ini adalah untuk meningkatkan manajemen pengelolaan bank sampah di Perumahan Taman Nuri berdampak meningkatnya pelayanan yang cepat dan informasi yang diberikan kepada nasabah bank sampah menjadi lebih akurat dan relevan.

Solusi permasalahan yang telah diuraikan diatas adalah dengan penerapan sistem cloud untuk manajemen pengelolaan bank sampah yang dijelaskan pada table 1 .

Tabel 1.

Solusi dan Target Luaran

\begin{tabular}{|c|c|}
\hline Sulwi Masabh & Trget Laran \\
\hline 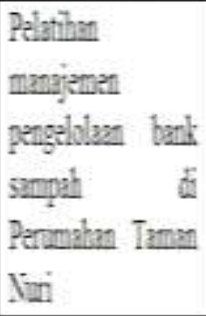 & 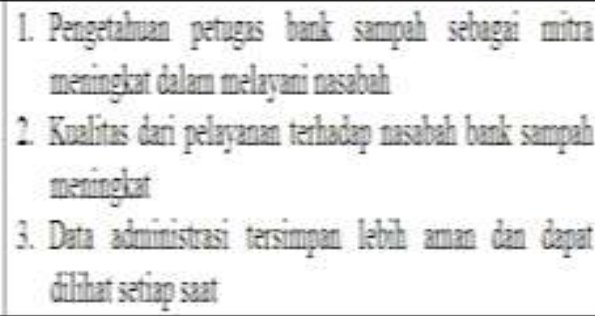 \\
\hline $\begin{array}{l}\text { Manjemen batk } \\
\text { sanph dengen } \\
\text { sistele doud }\end{array}$ & 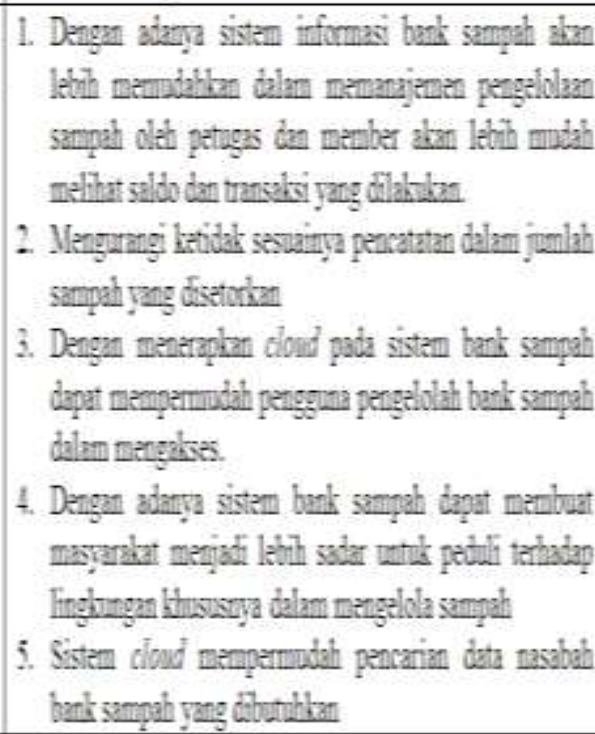 \\
\hline
\end{tabular}

\section{Metode Pelaksanaan}

Pengabdian masyarakat ini dilakukan oleh tim pelaksana dan mahasiswa yang turun langsung di penyampaian materi dan pemdampingan. Kegiatan berupa pelatihan dan pembuatan sistem tentang manajemen pengelolaan bank sampah berbasis sistem cloud. Pada kegiatan pengabdian masyarakat ini dilakukan 3 tahapan yaitu: 


\section{Persiapan Kegiatan}

Persiapan dilakukan dengan survey lapangan dan studi pustaka tentang manajemen pengelolaan bank sampah berbasis sistem cloud serta mempersiapkan kebutuhan untuk pelatihan dan pembuatan sistem dan menentukan waktu pelaksanaan dan lamanya kegiatan pengabdian masyarakat.

2. Pelaksanaan Kegiatan

Kegiatan pengabdian masyarakat ini dilengkapi dengan modul pelatihan dan pendampingan. Materi yang disampaikan pada kegiatan pengabdian masyarakat adalah sebagai berikut:

a. Pemberian materi dan pendampingan tentang manajemen pengelolaan bank sampah berbasis sistem cloud.

b. Praktek penerapan/implementasi sistem cloud untuk manajemen pengelolaan bank sampah.

c. Diskusi dan tanya jawab

3. Evaluasi Kegiatan

Untuk mencapai target tujuan pengabdian masyarakat ini, maka pada evaluasi kegiatan. Pelaksanaan evaluasi merupakan kegiatan penilaian yang dilaksanakan oleh tim pelaksana mulai dari persiapan sampai pasca program pelatihan, bimbingan teknis dan pendampingan. Fasilitas kegiatan ini ditujukan untuk mengukur indikator keberhasilan dan kelemahan yang mungkin ada dengan mencari faktor - faktor penyebabnya dan juga sebagai bahan penyusunan laporan dan rekomendasi kegiatan. Teknik evaluasi yang digunakan dalam mengevaluasi adalah pengamatan, wawancara dan penilaian khusus. Hasil evaluasi ini sebagai bahan rencana tindakan keberlanjutan program PKM di Perumahan Taman Nuri.

\section{Hasil dan Pembahasan}

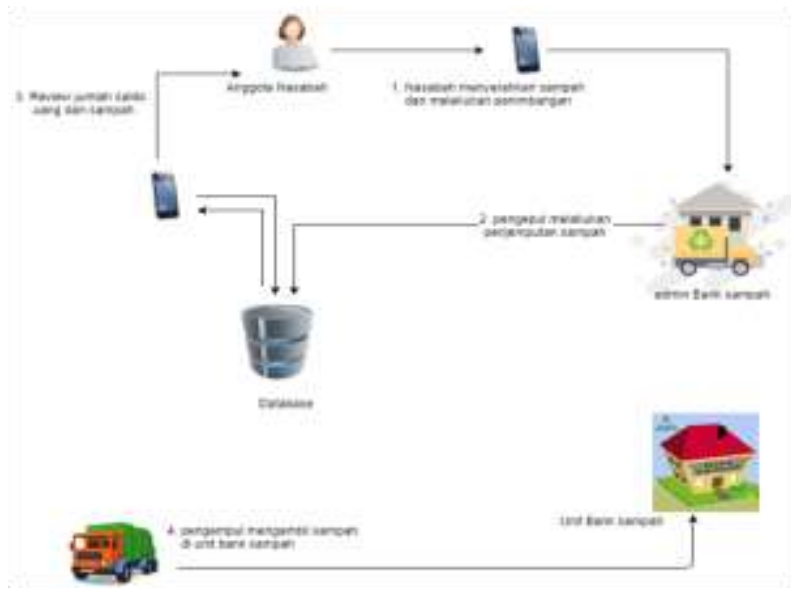

Gambar 2.

Diagram Konseptual manajemen bank sampah yang diusulkan
Gambar 2 merupakan gambaran iptek yang diusulkan yaitu anggota menyiapkan sampah yang akan disetorkan dan menginput jumlah sampah yang akan disetorkan kedalam sistem bank sampah berbasis web dan akan mengirim konfirmasi ke pengepul, selanjutnya pengepul menjemput sampah yang akan ditabung dan sampah akan dikumpulkan di tempat bank sampah jika jadwal bank sampah sudah selesai pengepul akan mengambil semua sampah yang telah terkumoul dibank sampah, dan anggota bisa melihat saldo yang telah terkumpul dan input sampah yang akan disetorkan, dapat dilihat pada gambar 3.

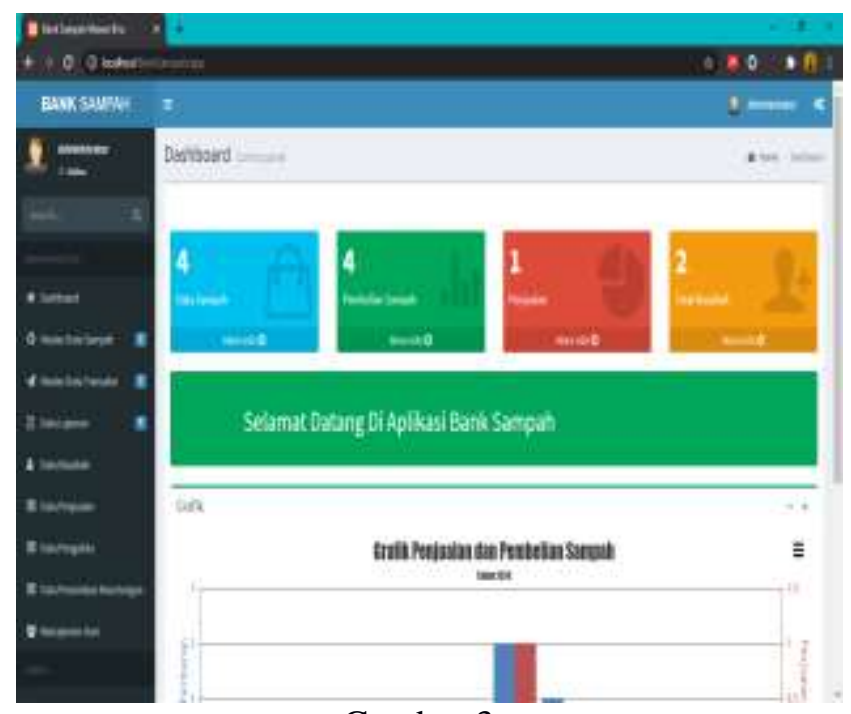

Gambar 3.

Tampilan sistem cloud manajemen bank sampah

Kegiatan pengabdian masyarakat berupa pelatihan ini dilengkapi dengan modul dan pendampingan. Materi yang disampaikan pada kegiatan pengabdian masyarakat adalah manajemen pengelolaan bank sampah berbasis sistem cloud. Pada proses yang kedua yaitu melakukan praktek sistem cloud untuk manajemen pengelolaan bank sampah, Kegiatan ini dapat dilihat pada gambar 4.

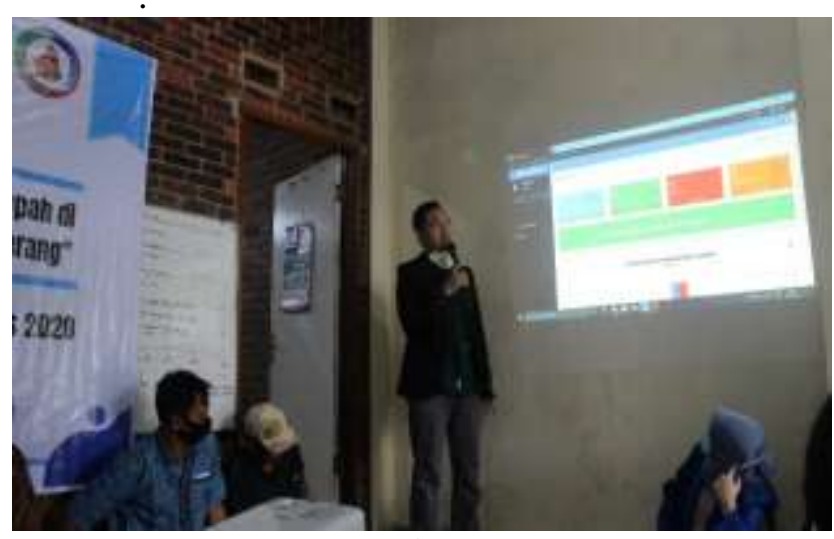

Gambar 4.

Praktek implementasi sistem cloud untuk manajemen pengelolaan bank sampah 
Proses selanjutnya adalah diskusi dan tanya jawab tentang materi yang sudah disampaikan. Pada proses ini peserta sangat antuis untuk menanyakan dan memberi masukan terkait manajemen pengelolaan bank sampah berbasis sistem cloud, dapat di lihat pada gambar 5 .

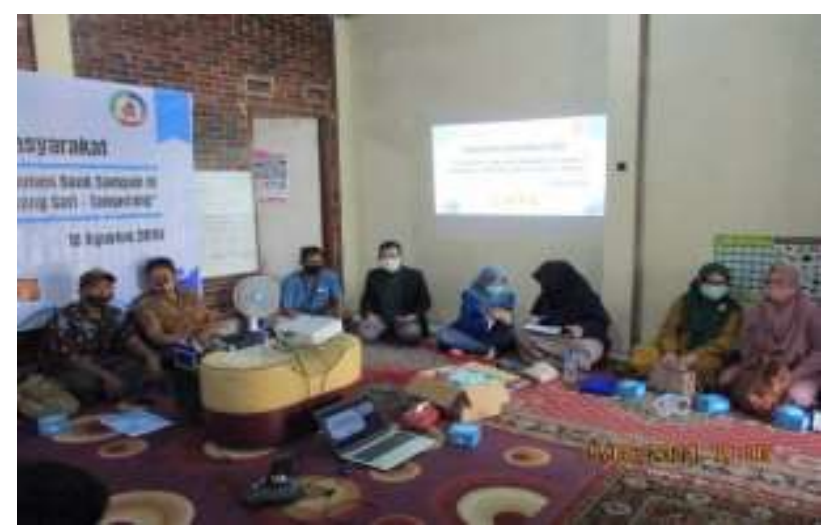

Gambar 5.

Diskusi dan tanya jawab

Kegiatan pengabdian masyarakat di Kelompok bank sampah perumahan taman nuri ini menfokuskan pada manajemen pengelolaan bank sampah berbasis sistem cloud, hal ini merupakan topik yang baru bagi warga di Kelompok bank sampah perumahan taman nuri .

Dengan metode penyuluhan dan pelatihan praktek serta pendampingan terhadap peserta kegiatan, pelatihan dilaksanakan dengan tujuan output yang dihasilkan pada pelatihan ini peserta kegiatan mempunyai ilmu yang baru dan dapat mengetahui mengenai manajemen pengelolaan bank sampah berbasis sistem cloud serta perkembangan teknologi untuk menghadapi era industri 4.0.

\section{Kesimpulan}

Dengan adanya web dalam manajemen bank sampah diharapkan sangat berguna sebagai sarana media informasi dalam memberikan layanan terhadap anggota atau nasabah agar lebih giat dalam mengumpulkan sampah dan menjaga lingkungan hidup, kemudian diharapkan proses laporan keuangannya menjadi lebih transparan. Pengembangan cloud terhadap sistem bank sampah dapat mempermudah operasional dalam manajemen bank sampah.

\section{Daftar Pustaka}

Alimuddin Yasin, MZ Yumarlin, T. F. (2017). Analisis Kebutuhan Sistem Informasi di LPK RJ-COMP Yogyakarta. Seminar Nasional Informatika (SNIf), 1(1), 111-116.
Jastam, M. S. (2015). Pemberdayaan Masyarakat Melalui Pengelolaan Sampah (Studi Kasus di Bank Sampah Pelita Harapan , Kelurahan Ballaparang, Kecamatan Rappocini, Makassar). Higiene, 1(1), 42-48. http://journal.uinalauddin.ac.id/index.php/higiene/article/vie $\mathrm{w} / 1217$

Sampah, M. B. (2015). Pengelolaan Sampah Berbasis Masyarakat Melalui Bank Sampah. Indonesian Journal of Conservation, 4(1), 83-94.

Selomo, M., Birawida, A. B., \& Mallongi, A. (2016). Bank Sampah Sebagai Salah Satu Solusi Penanganan Sampah Di Kota Makassar. Jurnal MKMI, 12(4), 232-240.

Suryani, A. S. (2014). Peran Bank Sampah Dalam Efektivitas Pengelolaan Sampah (Studi Kasus Bank Sampah Malang). Jurnal Aspirasi, 5(1), 71-84.

Ulum, M. B., \& Laday, R. K. (2016). Prototype Sistem Informasi Manajemen Bencana Alam. 28-29. 